\title{
Meeting report \\ The Fourth International Symposium on the Intraductal Approach to Breast Cancer, Santa Barbara, California, 10-13 March 2005
}

\author{
Bonnie L King ${ }^{1}$, Susan M Love ${ }^{2}$, Susan Rochman ${ }^{2}$ and Julian A Kim ${ }^{3}$
}

${ }^{1}$ Biology Department, Quinnipiac University, Hamden, Connecticut, USA

${ }^{2}$ Dr Susan Love Breast Cancer Research Foundation, Pacific Palisades, California, USA

${ }^{3}$ Cleveland Clinic Foundation, Cleveland, Ohio, USA

Corresponding author: Bonnie L King, bonnie.king@quinnipiac.edu

Published: 20 July 2005

This article is online at http://breast-cancer-research.com/content/7/5/198

(c) 2005 BioMed Central Ltd
Breast Cancer Research 2005, 7:198-204 (DOI 10.1186/bcr1288)

and representation of collected fluids, and to facilitate the introduction of therapeutic agents directly into the glandular lumina. Intraductal fluids and cells have been evaluated by a wide variety of genetic, epigenetic, and proteomic analyses, providing new insights into the biology of the normal and diseased breast. The 4th International Symposium on the Intraductal Approach to Breast Cancer, hosted by the Dr Susan Love Breast Cancer Research Foundation and held in Santa Barbara, California on 10-13 March 2005, provided a forum for the exchange and evaluation of these cumulative research findings. Over 100 delegates attended the meeting, including clinicians, basic scientists, translational investigators, and breast cancer advocates. The program included talks by 39 invited speakers and 11 pilot grant presenters in sessions covering the evaluation of intraductal approaches for breast cancer detection, risk assessment, intraductal therapies, and investigating normal breast biology.

\section{Nipple aspiration fluid: lessons learned and questions raised}

Several presentations reviewed and updated information from earlier nipple aspiration fluid (NAF) studies. Nicholas Petrakis (University of California, San Francisco, CA, USA) summarized his extensive body of research on breast fluids, showing that NAF production is associated with a constellation of factors, including age, race, menopausal status, and diet [2]. He also reviewed work performed in collaboration with Margaret Wrensch (University of California, San Francisco, CA, USA) that showed that the production and cytologic properties of NAF are associated with breast cancer risk [5,7]. Long-term follow up of women undergoing nipple aspiration revealed that the risk for developing breast cancer was two to five times greater for women diagnosed with cytologic atypia relative to those who did not yield any

$\mathrm{ER}=$ estrogen receptor; $\mathrm{FISH}=$ fluorescent in situ hybridization; $\mathrm{LOH}=$ loss of heterozygosity; NAF = nipple aspirate fluid; $\mathrm{QM}-\mathrm{MSP}=\mathrm{quantitative}$ multiplex, methylation-specific polymerase chain reaction; $\mathrm{PCR}=$ polymerase chain reaction. 
fluid. In these studies, women who yielded acellular fluid or fluid with normal cells were also at increased risk relative to nonyielders, leading Dr Petrakis to conclude that, 'yielding fluid is a precursor of something going on in the breast.'

Gertrude Buehring (University of California, Berkeley, CA, USA) presented the 20-year follow up of her prospective observational cohort including 1605 asymptomatic women who donated NAF between 1973 and 1976. Although the study found no elevated risk among women who had acellular fluid, there was a significant relative risk of 1.57 for women who had fluid with epithelial cells. For premenopausal women, the relative risk was 2.1. Based on these findings, $\mathrm{Dr}$ Buehring concluded that, "NAF epithelial cells may be a general indicator of breast pathology and their presence is associated with a subsequent increase in breast cancer risk.'

Although these data confirm that NAF-yielding women have a higher subsequent risk for developing breast cancer, it has never been confirmed that NAF-yielding ducts are the ducts at highest risk. In 1999 a microcatheter device was developed to cannulate and lavage individual ductal systems (ductal lavage) for the purpose of collecting higher numbers of cells from the terminal regions of the mammary tree [8]. Nipple aspiration has been used in conjunction with ductal lavage for the purpose of selecting ducts for cannulation. Susan Love (Dr Susan Love Breast Cancer Research Foundation, Pacific Palisades, CA, USA) framed two assumptions upon which this practice has been based: NAFproducing ducts are the most likely to be abnormal; and in cancerous breasts the ducts with cancer will yield NAF with malignant cells, whereas the other ducts will yield NAF with atypia. However, recent findings have called these assumptions into question. Two ductal lavage studies in which nonproductive ducts were cannulated $[9,10]$ have revealed the presence of atypia in dry ducts, and Carol Fabian's group (University of Kansas, Kansas City, KS, USA) demonstrated cytologic atypia by random periareolar fine needle aspiration in $16 \%$ of women who did not express NAF [11]. In addition, the selective cannulation of only the NAFyielding ducts in ductal lavage studies performed in women with cancer and ductal carcinoma in situ has been associated with low sensitivity for detecting cancer [12-14]. These findings suggest that the hypothesis that NAFproducing ducts are more likely to be abnormal needs to be revisited, and two of the presentations addressed this issue.

David Euhus (University of Texas Southwestern Medical Center, Dallas, TX, USA) described the results of his ductal lavage study conducted in 125 women [10]. All of the women's NAF-producing ducts were cannulated; in addition, cannulation of at least one dry duct was attempted per woman. Eighty per cent of the patients expressed NAF, and on average three ducts per patient were lavaged. Dr Euhus found that the cytologic atypia rate was identical for NAFproducing ducts and dry ducts, and that the atypia rate was similar for women who had high and low Gail scores. In addition, atypia declined as women aged. Based on these findings Dr Euhus concluded that, 'NAF production is not associated with lavage atypia' and 'five-year Gail risk over 1.7 percent does not predict lavage atypia.'

Susan Love reported initial findings from her foundation's Normal Breast Study. To date, 127 wet (NAF-producing) and dry ducts have been lavaged in 31 women who are not at high risk for breast cancer, and the fluids were analyzed for the presence of protein and cells. Fifty per cent of the NAFproducing ducts contained protein, as did 56\% of the dry ducts. Epithelial cells were found in $38 \%$ of the NAF-yielding ducts and $27 \%$ of the dry ducts. These results raise questions about what is being lavaged, and underscore the need to correlate ductal anatomy and physiology. Collectively, the paradoxical findings of these NAF studies generate questions about the biological significance of breast fluid and its relationship to cellularity, cytologic atypia, and breast cancer risk.

\section{Clinical utility of ductal lavage and mammary ductoscopy}

Several presentations highlighted the current status of the clinical applications of ductal lavage and mammary ductoscopy in the diagnosis and treatment of breast diseases. Seema Khan (Northwestern University School of Medicine, Chicago, IL, USA) presented data in which ductal lavage was performed on women with breast cancer immediately prior to therapeutic or prophylactic mastectomy to determine the diagnostic accuracy of the lavage results [13]. Any duct that yielded NAF was lavaged and no direct attempt was made to lavage the ducts with cancer. In $50 \%$ of cases, the cancer-containing ducts did not yield NAF, and the sensitivity of ductal lavage in confirming carcinoma based on routine cytopathology was approximately 20\%. Similar data presented by Edi Brogi (Memorial Sloan-Kettering Cancer Center, New York, NY, USA) confirmed a low sensitivity of ductal lavage in predicting the presence of known cancer, even in mastectomy specimens in which intraductal dye injection confirmed that the cancer-containing duct was being lavaged [12]. These studies reveal the limitations of using ductal lavage for screening, and the presenters concluded that those patients who are currently undergoing ductal lavage must be followed carefully by routine imaging methods even in the absence of atypical cytology.

With respect to current usage of ductal lavage in the clinic, Freya Schnabel (Columbia Presbyterian Medical Center, New York, NY, USA) and Gillian Mitchell (Peter MacCallum Cancer Center, Melbourne, Australia) presented data that highlighted high-risk patient decision making based on a multimodal approach using ductal lavage in combination with genetic testing and surveillance magnetic resonance imaging. Allison Kurian (Stanford University Medical School, Palo Alto, CA, USA) presented preliminary data on magnetic resonance imaging galactography that suggested that ductal lavage of 
two to three ductal systems could encompass approximately $30-50 \%$ of the breast ductal system. Katherine Lee (Cleveland Clinic Foundation, Cleveland, OH, USA) reported results on the use of ductal lavage in African-American patients with known breast cancer that demonstrated significant rates of atypia in the ipsilateral breast, suggesting that ductal lavage may be of some use in identifying high-risk African-American women who are not identified based upon the Gail model index alone. Finally, Jeff Tice (University of California, San Francisco, CA, USA) presented interesting data analyzing a cohort of over 6900 asymptomatic women with over 14 years follow up that suggested that NAF cytology may increase the predictive value of the Gail model [15].

Shahla Masood (University of Health Sciences, Jacksonville, FL, USA) summarized the challenges associated with breast fluid cytomorphology and reviewed its utility for breast cancer risk prediction in fine needle aspirate biopsies, NAF, and ductal lavage. Although she concluded that it is possible to use cytomorphology as a risk predictor, she emphasized that there is no current consensus on how cytology should be used in clinical practice, and underscored the need to further develop criteria to define prognostically relevant atypia in ductal lavage samples.

Mammary ductoscopy has been utilized in the intraoperative setting in patients with both benign and malignant breast conditions. William Dooley (University of Oklahoma Breast Institute, Oklahoma City, OK, USA) updated his large personal experience of using routine operative breast endoscopy with an emphasis on patients undergoing breastconserving lumpectomy for cancer [16]. He reported that more than $40 \%$ of patients undergoing lumpectomy for breast cancer were found to have proliferative changes (including atypical ductal hyperplasia) identified by ductoscopy, which were located more than $1 \mathrm{~cm}$ away from the primary breast tumor and outside of the standard lumpectomy resection cavity. Based on the resection of these proliferative lesions identified by ductoscopy, the annual hazard rate for local failure has been reduced from $0.67 \%$ to 0.08\%. Julian Kim (Cleveland Clinic Foundation, Cleveland, $\mathrm{OH}, \mathrm{USA}$ ) presented data from a similar trial in which the added value of ductoscopy-directed tissue resection was evaluated in patients undergoing standard lumpectomy for breast cancer. By contrast, although mammary ductoscopy did visualize the primary tumor and proliferative lesions in approximately $70 \%$ of the patients, many of these visualized abnormalities were within the standard lumpectomy resection cavity and thus offered no added benefit. Dr Kim also presented data comparing mammary ductoscopy and microductectomy with standard major duct excision in patients who present with pathologic nipple discharge, which suggested that microductectomy may identify fewer occult cancers due to the limited tissue sampling as compared with major duct excision. Two additional presentations by Volker
Mohammed Keshtgar (University College London, London, UK) outlined novel methods for enhancing the diagnostic accuracy of mammary ductoscopy by either real-time autofluorescence or optical interrogation of ductal tissue, which are currently being translated from the preclinical to early clinical stages.

The controversies surrounding the current clinical use of ductal lavage and mammary ductoscopy were debated by Seema Khan, Victor Vogel (University of Pittsburgh Medical School, Pittsburgh, PA, USA), William Dooley, and Julian Kim. Arguments for the use of ductal lavage included the strong evidence that atypical ductal hyperplasia is correlated with an elevated risk for breast cancer development, and those patients diagnosed with atypia by ductal lavage do have the opportunity to consider preventive measures. An opposing viewpoint was presented that contends that, because of the low sensitivity and specificity of ductal lavage, the procedure is not accurate in identifying high-risk patients based on cytology alone and may carry significant risk for false-negative findings. The debate surrounding mammary ductoscopy revolved around whether proliferative lesions, including atypical ductal hyperplasia, identified by mammary ductoscopy during breast-conserving lumpectomy for primary breast cancer are clinically useful markers of risk for locoregional recurrence or should be included in the surgical resection specimen. Most of the panel members agreed that well designed clinical trials with appropriate follow up will be necessary to shed light on these areas of controversy.

\section{Breast fluid biomarkers}

The sensitivity of intraductal approaches to detect or predict breast cancer is a compound measurement that reflects both the sampling and analysis of fluids. Although cytology has been used as the 'gold standard' in early studies to evaluate breast fluids for risk assessment and cancer detection, it has been proven to have low sensitivity for detecting malignancy and reveals a high degree of prognostically ambiguous atypia. In an effort to address these issues, the analysis of breast fluids has been extended to a large variety of biomarkers.

Some investigators have taken an in situ approach in order to colocalize markers and cytology to the same cells. Savitri Krishmanurthy (MD Anderson Cancer Center, Houston, TX, USA) described the use of interphase fluorescent in situ hybridization (FISH) to measure chromosomal aneusomy on previously Pap-stained NAF cytology specimens [17]. In previous studies she detected aneusomy in all of the cytologically malignant but only a subset of the cytologically atypical samples. She discussed the potential utility of FISH as an adjunct for confirming benign and malignant cytologic findings, and for further stratifying the classification of cytologic atypia. In a similar strategy to preserve cytomorphologic analysis, JianYu Rao (UCLA, Los Angeles, CA, USA) used quantitative fluorescence image analysis to analyze markers in ductal lavage thin prep specimens. 
Measurement of DNA 5cER (exceeding rate) content and Gactin overexpression in a small validation study resulted in $100 \%$ sensitivity and $100 \%$ specificity, suggesting that biomarker analysis may have better potential for separating cancer and noncancer samples than cytology.

Breast fluid specimens typically contain large numbers of infiltrating cells as well as benign epithelial cells, creating a 'needle in a haystack' challenge for biomarker development. Methylation-specific PCR is particularly well suited to this task because of its ability to detect rare cells containing cancer-associated DNA methylation events [18,19]. Sara Sukumar (Johns Hopkins University, Baltimore, MD, USA), who pioneered the application of these assays to ductal fluids, reported on her latest work to transition this approach from a subjective, gel-based method into an objective, automated, quantitative assay, termed QM-MSP (quantitative multiplex methylation-specific PCR). This approach combines the power of multiplex and real-time PCR to detect methylation events simultaneously at multiple loci, and increases the sensitivity of the approach to 1 in $10^{4}-10^{7}$ copies of DNA [20]. In a pilot study with Savitri Krishnamurthy and Henry Kuerer (MD Anderson Cancer Center, Houston, TX, USA), QM-MSP analysis was applied to Pap-stained NAF cytology slide cell scrapings. Analyzing a panel of 10 loci, methylated alleles were detected in all of the malignant, a subset of the atypical, and none of the normal samples. Dr Sukumar is currently working to apply QM-MSP to breast fluids collected by NAF, ductal lavage, and fine needle aspiration, as well as plasma.

Edward Sauter (University of Missouri, Columbus, MO, USA) also described the application of hypermethylation assays to DNAs extracted from 22 matched pairs of NAF and breast tumor tissue samples collected from breast cancer patients [19]. Using a panel of six loci, he detected hypermethylation in all of the malignant tissues and identical methylation patterns in $82 \%$ of the matched NAF specimens. No hypermethylation was detected in the normal tissues. He also used a panel of 11 microsatellite markers to evaluate matched specimens for loss of heterozygosity ( $\mathrm{LOH}$ ), and microsatellite instability [21]. Identical alterations were identified in $43 \%$ of fluids from matched cancer tissues harboring changes. Luciane Cavalli (Georgetown University, Washington, DC, USA), working to develop early detection strategies for BRCA1 mutation carriers, reported on the development of protocols to isolate free DNA from the acellular fraction of ductal lavage fluids for molecular evaluation, an approach that leaves the cellular fraction intact for cytologic analysis [22]. Using PCR-based approaches on these DNAs, she demonstrated $\mathrm{LOH}$ at the BRCA1 locus in four out of nine known BRCA1 mutation carriers. Gillian Mitchell and Imogen Locke (The Royal Marsden NHS Foundation Trust, London, UK) also reported detection of $\mathrm{LOH}$ at the BRCA1 and BRCA2 loci in ductal lavage fluids from $B R C A$-positive women. Finally, Sauter and Cavelli also described the detection of DNA mutations in mitochondrial DNA extracted from breast fluids - an advantageous approach because of the relative abundance of mitochondrial versus nuclear DNA [22,23].

There were also two presentations describing the application of SELDI-TOF/MS (surface-enhanced laser desorption and ionization-time of flight/mass spectrometry) to nipple aspirate fluids. Timothy Pawlik (MD Anderson Cancer Center, Houston, TX, USA) analyzed the proteomic profiles of fluids collected from the diseased and contralateral breasts of 23 breast cancer patients, and compared these with the profiles of fluids collected from 10 healthy control inidividuals [24]. Significant differences in the profiles between the fluids collected from patients and control inidividuals were detected, but interestingly the proteomic profiles of the cancerous and contralateral breast fluids of breast cancer patients were highly conserved. Sascha Dua (Royal Marsden Hospital Foundation Trust, London, UK) reported on her experience to date with a small pilot set of nipple aspirate fluids. In keeping with the observations presented by Pawlik, they also identified differentially expressed peaks between cancer and control fluids, but no significant differences between fluids from the healthy and cancerous breasts of the same patient. Both groups are working on identifing the protein peaks and will follow up with validation studies.

Seema Khan summarized a body of work describing the pathophysiology of the estrogen receptor (ER) in the human breast, exploring its potential significance as a marker of proliferation, and is currently performing studies to evaluate ER in breast fluid cells. Highlighting the potential use of intraductal approaches in chemoprevention trials, Arun Banu (MD Anderson Cancer Center, Houston, TX, USA) summarized preliminary results from a phase II prevention trial designed to test whether celecoxib induces changes in proliferation and apoptosis in the breast tissue of high-risk women. Using fine needle aspiration and ductal lavage samples, she observed significant downregulation of ER expression within 6 months of treatment. She is also in the process of analyzing other markers of proliferation and apoptosis.

Collectively, these studies demonstrate the successful application of biomarkers to detect breast cancer associated genetic, epigenetic, and proteomic abnormalities in breast fluids collected by a variety of intraductal techniques. In keeping with a growing body of published studies, markers appear to have superior sensitivity for breast cancer detection compared with cytology $[14,17-23,25]$. Ed Sauter concluded his talk with the comment that no single marker has adequate sensitivity to detect all malignancies, and an important goal will be to create systematically a panel of markers with high sensitivity and specificity. The successful evaluation and validation of breast cancer detection biomarkers in breast fluids will require the accurate sampling of ducts associated with lesions. 


\section{Spotlight on the future: intraductal therapy}

The session that highlighted intraductal therapy approaches demonstrated the rapid translation of preclinical testing to early phase human clinical trials. Sara Sukumar presented compelling data in a murine model of HER2/transgenic mice demonstrating that intraductal administration of pegylated liposomal doxorubicin (Doxil ${ }^{\circledR}$, ALZA Corporation, Mountain View, CA, USA) into mammary ducts prevented the formation of mammary tumors and resulted in equivalent or superior antitumor effects in a therapy model against established tumors with less systemic toxicity as compared with intravenous administration. Robert Goulet Jr (Indiana University Medical Center, Indianapolis, IN, USA) presented pilot study data on the feasibility of mammary intraductal administration of either nanoparticles or Doxil in breasts removed by mastectomy. In a majority of patients infused with nanoparticles, the particles were confirmed to traverse into the terminal lobules by fluorescence microscopy. M Ellen Mahoney (Arcata, CA, USA) presented the first in vivo use of intraductal Doxil describing a safety pilot in a woman two months prior to a planned prophylactic mastectomy. The procedure was done under local anesthesia with no acute toxicity. Several new concept protocols were discussed at the end of the session, which highlighted pilot studies of intraductal delivery of either liposome or nanoparticleassociated cytotoxic agents in patients with breast cancer.

\section{Window on mammary gland biology}

In his introductory remarks, Nick Petrakis (UCSF School of Medicine, San Francisco, CA, USA) referred to breast fluids as, "a 'stew' containing exfoliated epithelial cells, foam cells, lymphocytes, disintegrating cellular debris, milk proteins, fat globules, fatty acids, enzymes, immunoglobulins, and other chemical substances derived from endogenous and exogenous sources". As such, ductal fluids reflect the microenvironment of the breast and constitute a surrogate with which to study the biology of the human mammary gland.

One of the key insights to emerge from intraductal studies is the degree to which the mammary gland is infiltrated by systemic cells. In fact, the most frequently observed cell type in breast fluids has consistently been the mammary foam cell, the origin of which has been debated as epithelial versus macrophage for years. Sanford Barsky (Ohio State University, Columbus, $\mathrm{OH}, \mathrm{USA}$ ) presented elegant data from a transgenic mouse model in which labeled male bone marrow cells were transplanted into irradiated female recipients. Following the induction of psuedopregnancy to promote mammary gland development, labeled macrophages were observed in the mammary gland lumina. In another approach, he used interphase FISH to show the presence of $Y$ chromosomes in breast tumor tissue macrophages from breast cancer patients who had previously received bone marrow transplants from male donors. Previous studies have revealed that ductal lavage samples from breast cancer
Bonnie King (Quinnipiac University, Hamden, CT, USA) presented data showing that large numbers of macrophages are also present in cytologically benign breast fluids collected from healthy, asymptomatic women recruited from the general population. The presence of large numbers of intraductal macrophages in healthy breast ducts are in keeping with observations in a mouse model system showing that macrophages are recruited to and within the growing end buds of the mammary gland during ductal morphogenesis [28]. Sanford Barsky ended his talk by stating that characterization of the crosstalk between the infiltrating cells and resident breast cells will be critical to our understanding of mammary gland biology and breast cancer.

The minimally invasive nature of intraductal approaches permits serial sampling, so that the breast tissue can be measured as a function of physiologic and intervention variables. Robert Chatterton (Northwestern University, Chicago, IL, USA) reported on his studies to evaluate breast fluids as a method for assessing the hormonal status of the breast $[29,30]$. In keeping with other reports [4,31], he reported that estradiol and progesterone are concentrated up to 10-fold in NAF relative to serum. Bonnie King presented immunocytochemical data showing that intraductal macrophages express aromatase, suggesting a potential mechanism for the estradiol gradient. Dr Chatterton also reported that although NAF estradiol levels were stable during the menstrual cycle and over a period of 15 months in premenopausal women, they decreased dramatically in association with exercise and with oral contraceptive usage. $\mathrm{He}$ also showed that estrogen-responsive proteins correlated with estrogen levels, concluding that hormone concentrations in NAF are good predictors of the activities.

Many substances associated with the growth, development, and tumorigenesis of the breast have been detected in breast fluids. Although some of these substances are secreted by resident and infiltrating cells, others traverse the ductal epithelium via transcellular and paracellular pathways. Do these substances turn over on a regular basis, or does the intraductal compartment represent a 'stagnant pond', potentially harboring the accumulation of bioactive substances? Fernando Mannello (University 'Carlo Bo', Urbino, Italy) presented his hypothesis that breast fluid composition is determined largely by the type of intercellular junctional complexes within the ductal epithelium [32-34]. In previous work using SDS-PAGE analysis, he observed two biochemically distinct types of NAF. Type I NAF, found in healthy control women, had protein profiles similar to plasma, whereas type II fluid, observed in a high proportion of breast cancer patients, resembled breast tumor cytosol extracts. Ultrastructural analysis has suggested that type I NAF is associated with the presence of leaky tight junctions, allowing for the unrestricted movement of substances in and out of the ductal compartment. Type II NAF is associated with the presence of tight and gap junctions that seal the ductal epithelium. 
Nick Petrakis suggested that age-related decreases in the reabsorption of breast fluid may lead to prolonged exposure of the breast epithelium to chemical substances in NAF that may lead to breast cancer. Karl Karnaky (Medical University of South Carolina, Charleston, SC, USA) is studying the membrane transporter MRP2 (multidrug resistance associated protein transporter), which is located on the apical surfaces of exocrine gland epithelial cells and transports a variety of endogenous and exogenous substances into the breast ducts [35]. He pointed out that, "breast ductules are the most unusual exocrine glands in the body in that they may never be flushed', leading to the potential concentration of protective as well as deleterious substances within the luminal compartment of the gland. He is currently studying the dynamics of transport using cultured breast epithelial cells, with the goal of unravelling the uptake and regulation of protective substances such as antioxidants and chemotherapeutic agents, as well as deleterious substances such as steroids and carcinogens.

\section{Pilot grants}

The Dr Susan Love Research Foundation used an expedited grant review mechanism to distribute pilot grants at the Symposium. Applicants submitted one-page abstracts and responsive proposals were selected for presentation at the meeting. A multidisciplinary peer review committee, composed of basic scientists, breast cancer activists, and physicians, evaluated the proposals and presentations at the meeting. This year, 11 researchers presented proposals. At the close of the Symposium, the Foundation provided a total of $\$ 85,000$ to support the pilot work of seven promising researchers utilizing the intraductal approach for a wide range of projects.

The 2005 recipients were: Patricia Berg, PhD (George Washington University Medical Center), 'Expression of BP1 in ductal lavage samples from women at risk for breast cancer'; Brian K Petroff, DVM, PhD (University of Kansas Medical Center), 'Laser capture microdissection and real time polymerase chain reaction to assess breast biomarker gene expression following random periareolar fine needle aspiration and ductal lavage'; Ferdinando Mannello, PhD (University 'Carlo Bo'), 'Bio-molecular characterization and cytometric evaluation of nipple aspirate fluids to identify biomarkers of breast cancer'; Scott L Kominsky, PhD (The Johns Hopkins University School of Medicine), 'Intraductal nanopolymer drug delivery for breast cancer prevention and therapy'; Regina Brown, MD (The Johns Hopkins University School of Medicine), 'The feasibility and safety of intraductal administration of pegylated liposomal doxorubicin (Doxil) in women'; Edna K Valdes, MD (Beth Israel Medical Center), 'Is persistent nipple aspirate fluid in women on tamoxifen prognostic for adverse breast events?'; and Gertraud Maskarinec, MD, PhD (University of Hawaii), 'Short-term effects of soy on estrogens and breast cell proliferation in nipple aspirate fluid'.

\section{Conclusion}

The 4th Symposium on the Intraductal Approach to Breast Cancer revealed an active and growing network of investigators committed to the development of intraductal approaches. Although much progress has been made since the first symposium was held in 1999, this year's meeting distilled many new challenges and goals. Progress toward these goals, along with the results of this year's pilot grant projects, will be presented at the 5th Intraductal Symposium on the Intraductal Approach to Breast Cancer in 2007.

\section{Competing interests}

Susan Love is a consultant to Cytyc, Pepsico, and Pacificare, and is on the Board of Sanarus.

\section{Acknowledgements}

This conference was supported in part by Acueity, The American Cancer Society, Amgen, The Barbara Ireland Walk for the Cure, The California Breast Cancer Research Program, Ciphergen, Cytyc, The Dublin Marathon Training Group 2004, NCl - Division of Cancer Prevention, and The Office of Research on Women's Health, NIH.

\section{References}

1. Papanicolaou GN, Holmquist DG, Bader GM, Falk EA: Exioliative cytology of the human mammary gland and its value in the diagnosis of cancer and other diseases of the breast. Cancer 1958, 11:377-409.

2. Petrakis NL, Mason L, Lee R, Sugimoto B, Pawson S, Catchpool $\mathrm{F}$ : Association of race, age, menopausal status, and cerumen type with breast fluid secretion in nonlactating women, as determined by nepple aspiration. J Natl Cancer Inst 1975, 54: 829-834.

3. Sartorius OW, Smith HS, Morris P, Benedict D, Friesen L: Cytologic evaluation of breast fluid in the detection of breast disease. J Natl Cancer Inst 1977, 59:1073-1080.

4. Rose DP, Lahti H, Laakso K, Kettunen K, Wynder EL: Serum and breast duct fluid prolactin and estrogen levels in healthy Finnish and American women and patients with fibrocystic disease. Cancer 1986, 57:1550-1554.

5. Wrensch MR, Petrakis NL, King EB, Miike R, Mason L, Chew KL, Lee MM, Ernster VL, Hilton JF, Schweitzer R, et al.: Breast cancer incidence in women with abnormal cytology in nipple aspirates of breast fluid. Am J Epidemiol 1992, 135:130-141.

6. Buehring GC: Screening for breast atypias using exfoliative cytology. Cancer 1979, 43:1788-1799.

7. Wrensch MR, Petrakis NL, Miike R, King EB, Chew K, Neuhaus J, Lee MM, Rhys M: Breast cancer risk in women with abnormal cytology in nipple aspirates of breast fluid. J Nat/ Cancer Inst 2001, 93:1791-1798.

8. Dooley WC, Ljung BM, Veronesi U, Cazzaniga M, Elledge RM, O'Shaughnessy JA, Kuerer HM, Hung DT, Khan SA, Phillips RF, et al:: Ductal lavage for detection of cellular atypia in women at high risk for breast cancer. J Nat/ Cancer Inst 2001, 93:1624-1632.

9. Kurian AW, Mills MA, Jaffee M, Sigal BM, Chun NM, Kingham KE, Collins LC, Nowels KW, Plevritis SK, Garber JE, et al.: Ductal lavage of fluid-yielding and non-fluid-yielding ducts in BRCA1 and BRCA2 mutation carriers and other women at high inherited breast cancer risk. Cancer Epidemiol Biomarkers Prev 2005, 14:1082-1089.

10. Maddux AJ, Ashfaq R, Naftalis E, Leitch AM, Hoover S, Euhus D: Patient and duct selection for nipple duct lavage. Am J Surg 2004, 188:390-394.

11. Sharma P, Klemp JR, Simonsen M, Welsko CM, Zalles CM, Kimler $\mathrm{BF}$, Fabian CJ: Failure of high risk women to produce nipple aspirate fluid does not exclude detection of cytologic atypia in random periareolar fine needle aspiration specimens. Breast Cancer Res Treat 2004, 87:59-64.

12. Brogi $E$, Robson M, Panageas KS, Casadio C, Ljung BM, Montgomery L: Ductal lavage in patients undergoing mastectomy for mammary carcinoma: a correlative study. Cancer 2003, 98: 2170-2176. 
13. Khan SA, Wiley EL, Rodriguez N, Baird C, Ramakrishnan R, Nayar $\mathrm{R}$, Bryk M, Bethke KB, Staradub VL, Wolfman J, et al:: Ductal lavage findings in women with known breast cancer undergoing mastectomy. J Natl Cancer Inst 2004, 96:1510-1517.

14. King BL, Tsai SC, Gryga ME, D'Aquila TG, Seelig SA, Morrison LE, Jacobson KK, Legator MS, Ward DC, Rimm DL, et al.: Detection of chromosomal instability in paired breast surgery and ductal lavage specimens by interphase fluorescence in situ hybridization. Clin Cancer Res 2003, 9:1509-1516.

15. Tice JA, Miike R, Adduci K, Petrakis NL, King E, Wrensch MR: Nipple aspirate fluid cytology and the Gail model for breast cancer risk assessment in a screening population. Cancer Epidemiol Biomarkers Prev 2005, 14:324-328.

16. Dooley WC, Spiegel A, Cox C, Henderson R, Richardson L, Zabora J: Ductoscopy: defining its role in the management of breast cancer. Breast J 2004, 10:271-272.

17. Krishnamurthy $S$, Zhao L, Hayes K, Glassman AB, Cristofanilli M, Singletary SE, Hunt KK, Kuerer HM, Sneige N: Feasibility and utility of using chromosomal aneusomy to further define the cytologic categories in nipple aspirate fluid specimens: a preliminary study. Cancer 2004, 102:322-327.

18. Evron E, Dooley WC, Umbricht CB, Rosenthal D, Sacchi N, Gabrielson E, Soito AB, Hung DT, Ljung B, Davidson NE, et al:: Detection of breast cancer cells in ductal lavage fluid by methylation-specific PCR. Lancet 2001, 357:1335-1336.

19. Krassenstein R, Sauter E, Dulaimi E, Battagli C, Ehya H, KleinSzanto A, Cairns P: Detection of breast cancer in nipple aspirate fluid by $\mathrm{CpG}$ island hypermethylation. Clin Cancer Res 2004, 10:28-32.

20. Fackler MJ, McVeigh M, Mehrotra J, Blum MA, Lange J, Lapides A, Garrett E, Argani P, Sukumar S: Quantitative multiplex methylation-specific PCR assay for the detection of promoter hypermethylation in multiple genes in breast cancer. Cancer Res 2004, 64:4442-4452.

21. Zhu W, Qin W, Ehya H, Lininger J, Sauter E: Microsatellite changes in nipple aspirate fluid and breast tissue from women with breast carcinoma or its precursors. Clin Cancer Res 2003, 9:3029-3033.

22. Isaacs $C$ Cavalli LR, Cohen $Y$, Pennanen $M$, Shankar LK, Freedman M, Singh B, Liu M, Gallagher A, Rone JD, et al.: Detection of LOH and mitochondrial DNA alterations in ductal lavage and nipple aspirate fluids from hngh-risk patients. Breast Cancer Res Treat 2004, 84:99-105.

23. Zhu W, Qin W, Bradley P, Wessel A, Puckett CL, Sauter ER: Mitochondrial DNA mutations in breast cancer tissue and in matched nipple aspirate fluid. Carcinogenesis 2005, 26:145152

24. Pawlik TM, Fritsche $H$, Coombes KR, Xiao L, Krishnamurthy $S$, Hunt KK, Pusztai L, Chen JN, Clarke CH, Arun B, et al:: Significant differences in nipple aspirate fluid protein expression between healthy women and those with breast cancer demonstrated by time-of-flight mass spectrometry. Breast Cancer Res Treat 2005, 89:149-157.

25. Yamamoto $D$, Senzaki $H$, Nakagawa $H$, Okugawa $H$, Gondo $H$, Tanaka K: Detection of chromosomal aneusomy by fluorescence in situ hybridization for patients with nipple discharge. Cancer 2003, 97:690-694.

26. King BL, Crisi GM, Tsai SC, Haffty BG, Phillips RF, Rimm DL: Immunocytochemical analysis of breast cells obtained by ductal lavage. Cancer 2002, 96:244-249.

27. Krishnamurthy S, Sneige N, Ordonez NG, Hunt KK, Kuerer HM: Characterization of foam cells in nipple aspirate fluid. Diagn Cytopathol 2002, 27:261-264; discussion 265.

28. Gouon-Evans V, Lin EY, Pollard JW: Requirement of macrophages and eosinophils and their cytokines/ chemokines for mammary gland development. Breast Cancer Res 2002, 4:155-164.

29. Chatterton RT Jr, Geiger AS, Khan SA, Helenowski IB, Jovanovic $\mathrm{BD}$, Gann $\mathrm{PH}$ : Variation in estradiol, estradiol precursors, and estrogen-related products in nipple aspirate fluid from normal premenopausal women. Cancer Epidemiol Biomarkers Prev 2004, 13:928-935.

30. Chatterton RT Jr, Geiger AS, Mateo ET, Helenowski IB, Gann PH: Comparison of hormone levels in nipple aspirate fluid of preand postmenopausal women: effect of oral contraceptives and hormone replacement. J Clin Endocrinol Metab 2005, 90: 1686-1691.
31. Ernster VL, Wrensch MR, Petrakis NL, King EB, Miike R, Murai J, Goodson WH, Siiteri P: Benign and malignant breast disease: Initial study results of serum and breast fluid analyses of endogenous estrogens. JNC/ 1987, 79:949-960.

32. Malatesta M, Mannello F, Sebastiani M, Cardinali A, Marcheggiani F, Reno F, Gazzanelli G: Ultrastructural characterization and biochemical profile of human gross cystic breast disease. Breast Cancer Res Treat 1998, 48:211-219.

33. Sanchez LM, Vizoso F, Diez-Itza I, Lopez-Otin C: Identification of the major protein components in breast secretions from women with benign and malignant breast diseases. Cancer Res 1992, 52:95-100.

34. Malatesta M, Mannello F, Bianchi G, Sebastiani M, Gazzanelli G: Biochemical and ultrastructural features of human milk and nipple aspirate fluids. J Clin Lab Anal 2000, 14:330-335.

35. Karnaky KJ, Jr., Hazen-Martin D, Miller DS: The xenobiotic transporter, MRP2, in epithelia from insects, sharks, and the human breast: implications for health and disease. J Exp Zoolog $A$ Comp Exp Biol 2003, 300:91-97. 